\title{
Relationship between asthma and gastro-oesophageal reflux
}

\author{
ROBERT J R GOODALL, JOHN E EARIS, DAVID N COOPER, ALAN BERNSTEIN, AND \\ JOHN G TEMPLE
}

From the Department of Thoracic Medicine and University Department of Surgery, Hope Hospital, Salford

ABSTRACT Twenty patients with bronchial asthma who also had gastro-oesophageal reflux were investigated. The severity of their reflux was graded using symptom score of heartburn and regurgitation and by the following investigations: barium swallow and meal, fibreoptic endoscopy and biopsy, manometry and $\mathrm{pH}$ monitoring of the distal oesophagus, and an acid infusion test. Full lung function studies were performed and patients were entered into a double-blind crossover study using cimetidine to control their reflux in order to assess beneficial effects with respect to their respiratory problems. Eighteen patients completed the study. Significant improvements were seen in reflux and night time asthmatic symptoms, both these indices being measured on a scoring system. Home monitoring of peak flow values showed a statistical improvement for the last peak flow reading of the day. Fourteen patients felt that their chest symptoms had significantly improved during the cimetidine period.

Gastro-oesophageal reflux commonly produces symptoms in subjects of all ages. The dominant complaints are usually related to the upper gastrointestinal tract and include heartburn, regurgitation, and occasionally dysphagia. Patients with reflux are also liable to respiratory complications leading to severe, progressive, and disabling pulmonary damage. ${ }^{1}$ More recently attention has been drawn to an association between reflux and exacerbations of bronchial asthma, ${ }^{2} 3$ and there have been several studies suggesting subjective improvement in such patients after surgical correction of hiatus hernia. ${ }^{3-5}$

In this study we have attempted to demonstrate a measurable improvement in symptoms and respiratory function in a group of asthmatic patients, who also had well-documented reflux, by controlling their reflux with cimetidine in a double-blind, crossover trial.

\section{Methods}

Informed consent for study was obtained from 20 patients, 13 men and seven women, whose ages ranged from 30-65 years (mean 54 years). All patients had bronchial asthma and were attending

Address for reprint requests: Dr A Bernstein, Department of Thoracic Medicine, Hope Hospital, Eccles Old Road, Salford M6 8HD.

the Department of Thoracic Medicine outpatient clinic. All but one had symptomatic reflux.

The diagnosis of asthma was made mainly on clinical grounds (table 1). All patients had nocturnal wheezing and 13 had either a personal or family history of atopic disease. Nineteen patients showed a good response to the administration of disodium cromoglycate or corticosteroid drugs, but one patient was managed satisfactorily with bronchodilator therapy alone. Eleven patients had reversible airways obstruction, as demonstrated by an improvement of $20 \%$ or more in the forced expiratory volume in the first second after the inhalation of a broncho-

Table 1 Asthma characteristics of subjects studied

\begin{tabular}{|c|c|}
\hline $\begin{array}{r}\text { Average age at time of study (yr) } \\
\text { range (yr) }\end{array}$ & $\begin{array}{c}54 \\
30-65\end{array}$ \\
\hline $\begin{array}{r}\text { Average age at onset of asthma (yr) } \\
\text { range (yr) }\end{array}$ & $\begin{array}{l}37 \\
7-58\end{array}$ \\
\hline $\begin{array}{r}\text { Average duration of asthma symptoms (yr) } \\
\text { range (yr) }\end{array}$ & $\begin{array}{c}17 \\
1 \cdot 5-30\end{array}$ \\
\hline $\begin{array}{l}\text { Number/total number tested } \\
\text { Nocturnal cough or wheezing } \\
\text { Personal history of allergy or atopy } \\
\text { Family history of allergy } \\
\text { Good response to disodium cromoglycate } \\
\quad \text { steroids (inhaled or oral) }\end{array}$ & $\begin{array}{r}20 / 20 \\
7 / 20 \\
10 / 20 \\
12 / 16 \\
15 / 16\end{array}$ \\
\hline $\begin{array}{l}\text { Reversible airways obstruction } \\
\text { Blood eosinophilia }<0.5 \times 106 / 1 \\
\text { Sputum eosinophilia } \\
\text { Positive skin testing (common allergens) }\end{array}$ & $\begin{array}{r}11 / 20 \\
11 / 20 \\
4 / 16 \\
10 / 16\end{array}$ \\
\hline
\end{tabular}


dilator drug. Four of the remainder had no evidence of airways obstruction at the time of testing. Fourteen patients had either blood or sputum eosinophilia or both.

Details of the patients' gastrointestinal symptoms and investigation are shown in table 2 . The one patient with no gastrointestinal symptoms was included in the study when investigations to exclude aspiration as an aggravating or precipitating factor for his respiratory complaint, revealed reflux oesophagitis. Patients underwent the following investigations: barium swallow and meal, fibreoptic endoscopy and biopsy, manometry and $\mathrm{pH}$ monitoring of the distal oesophagus, ${ }^{6}$ and an acid infusion test. ${ }^{7}$ Two patients had no abnormality shown on any of these investigations but in view of their histories and symptoms, it was felt that they should be included in the study.

In this randomised double-blind crossover study, the patients were given a six-week supply of tablets which were either cimetidine $200 \mathrm{mg}$ or an identical placebo. For the second six-week period the other tablets were provided. Random allocation to receive active tablets in the first or second period was performed by the pharmacy department. Patients were instructed to take one tablet three times daily and two at night.

The patients recorded on a diary card a score of their day and night time asthmatic symptoms scaled as follows:

$$
\begin{gathered}
\text { Day time } \\
0 \text { - good day, no } \\
\text { wheezing } \\
1 \text { - wheezy for } 1-2 \\
\text { hours } \\
2 \text { - wheezy for much } \\
\text { of the day } \\
3 \text { - wheezy all day }
\end{gathered}
$$

$$
\begin{aligned}
& \quad \text { Night time } \\
& 0-\text { good night } \\
& 1 \text { - slept well, but } \\
& \text { slightly wheezy } \\
& 2 \text { - woken } 2-3 \text { times } \\
& \text { because of } \\
& \text { wheezing } \\
& 3 \text { - bad night, awake } \\
& \text { most of the time }
\end{aligned}
$$

The patients were provided with a Wright minipeak flow meter and recorded values immediately upon waking, 30-60 minutes later, mid-afternoon at a set time convenient for the patient, and upon retiring to bed. Three peak flow readings were taken at these times and the highest value entered on the diary card. The card was also used to record the daily use of inhaled bronchodilator drugs and whether any medication was missed or changed, for any reason.

At the time of entry into the study and at the end of each six-week period, the symptoms of reflux were also recorded as follows: 8

$\begin{gathered}\text { Heartburn } \\ 0 \text { - no heartburn } \\ 1 \text { - occasional } \\ \text { heartburn }\end{gathered}$
2 - heartburn requiring
antacids or medical
advice
3 - heartburn
constantly inter-
fering with
activities

\begin{tabular}{ll} 
& \multicolumn{1}{c}{ Regurgitation } \\
$0-$ & no regurgitation \\
$1-$ & occasional \\
& regurgitation on \\
& straining or \\
position change & predictable \\
2 - & pregurgitation on \\
& straining or \\
& position change \\
3 - & occurrence of \\
pulmonary \\
aspiration
\end{tabular}

Respiratory function measurements were made initially and after each trial period, using a precalibrated PK Morgan TLC Test spirometer. Functional residual capacity (FRC) was determined by the helium dilution technique ${ }^{9}$ and was followed by recording forced expiratory volume in the first second $\left(\mathrm{FEV}_{1}\right)$ and forced vital capacity (FVC). Total lung capacity (TLC) and residual volume (RV) were derived from these

\begin{tabular}{|c|c|c|}
\hline $\begin{array}{l}\text { Sympto } \mathrm{ns} \\
\qquad(\mathrm{n}=20)\end{array}$ & $\begin{array}{l}\text { Heartburn } \\
\text { Regurgitation } \\
\text { None }\end{array}$ & \\
\hline $\begin{array}{l}\text { Radiology } \\
\quad(n=19)\end{array}$ & $\begin{array}{l}\text { Sliding hiatal hernia } \\
\text { Reflux of barium } \\
\text { Both of above } \\
\text { No abnormality }\end{array}$ & $\begin{array}{r}9 \\
10 \\
6 \\
6\end{array}$ \\
\hline $\begin{array}{l}\text { Endoscopy } \\
\qquad(n=20)\end{array}$ & $\begin{array}{l}\text { Mild oesophagitis } \\
\text { Marked oesophagitis } \\
\text { Normal examination }\end{array}$ & $\begin{array}{l}7 \\
4 \\
9\end{array}$ \\
\hline $\begin{array}{l}\text { Lower oesophageal } \\
\text { manometry } \\
\quad(n=20)\end{array}$ & $\begin{array}{l}\text { Low pressure sphincter } \\
\text { Normal }\end{array}$ & $\begin{array}{r}8 \\
12\end{array}$ \\
\hline $\begin{array}{l}\text { Prolonged } \mathrm{pH} \\
\text { monitoring } \\
\quad(n=18)\end{array}$ & $\begin{array}{l}\text { Abnormal } \\
\text { Normal }\end{array}$ & $\begin{array}{r}8 \\
10\end{array}$ \\
\hline $\begin{array}{l}\text { Acid infusion test } \\
\quad(n=20)\end{array}$ & $\begin{array}{l}\text { Positive } \\
\text { Positive-unrelated } \\
\text { Negative }\end{array}$ & $\begin{array}{l}8 \\
3 \\
9\end{array}$ \\
\hline
\end{tabular}
traces. Flow-volume loops were recorded by incorporating into the Morgan spirometer a flowvolume differentiator and recording onto a Bryan's 26000 A3 X-Y plotter. Maximum expiratory flow rate (MEF) was recorded at $75 \%$ and $25 \%$ of the vital capacity and maximum midexpiratory flow rate (MMEFR) at $50 \%$ of vital capacity.

As the data are not normally distributed, values are presented as medians with the range of observations in parentheses. The analysis of the data was performed by a non-parametric method for crossover trials, first described by Koch ${ }^{10}$ and recently discussed by Hills and Armitage, ${ }^{11}$ using

Table 2 Gastro-oesophageal reflux characteristics of subjects studied 
a Mann-Whitney $U$ test. This test can be used to examine the data for carry-over effect as well as to determine the statistical significance of the results.

\section{Results}

Of the 20 patients entered into the study, 18 completed both trial periods. One patient, while on active tablets, had an acute exacerbation of her asthma and required prolonged inpatient treatment. The other patient failed to attend after the first six weeks, having taken placebo tablets. In the remaining 18 patients, 11 received placebo tablets for the first six weeks and seven received cimetidine.

The initial analysis of the data demonstrated that there was no significant carry-over effect with any of the measured indices and thus it was possible to test for treatment effect in every case by comparison of the results obtained at the end of each treatment period.

After cimetidine the reflux symptom score improved in 14 patients compared with the score after placebo, but in the other four patients was slightly worse. However the median values for the reflux symptom scores showed a significant improvement $(\mathrm{p}<0.02)$.

At the completion of the trial patients were asked which treatment period they had preferred with respect to their chest symptoms. In 14 this was the cimetidine period, in three the placebo period, and one had no preference.

There was objective evidence of improvement during the cimetidine period in that the median night time asthmatic scores fell significantly $(p<0.05)$. During the day however, although the median scores for asthma during the final three weeks for each period also fell with cimetidine, this improvement was not significant.

The peak flow values shown (table 3 ) are the median and range of patients' average values at each of the four readings over the final three weeks of the placebo and cimetidine periods. Although there was a trend for these peak flow readings to improve during cimetidine treatment, the difference between the two treatment periods was statistically significant only for the last reading of the day $(p<0.05)$. The majority of the peak flow improvements were minor and probably of little clinical significance. There was no difference in the frequency of use of inhaled bronchodilator or other therapy during each of the treatment periods. The full pulmonary function tests showed no significant change at the end of each treatment period.
Table 3 Results-median values and range

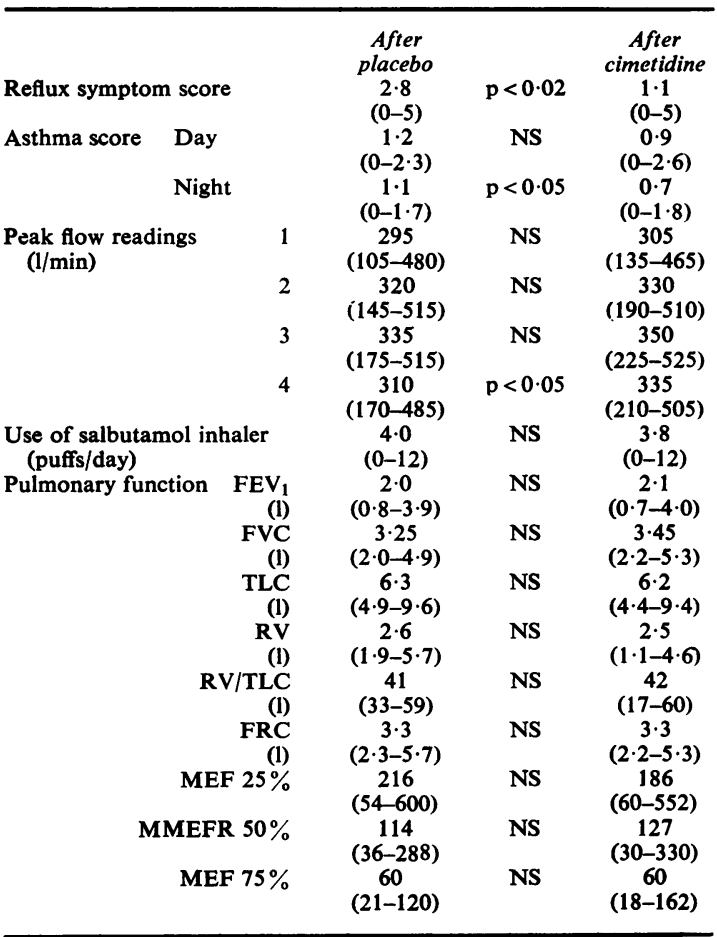

During the period on placebo tablets there was a correlation between the severity of both the reflux and asthmatic symptoms during the day $(r=0.46, p<0.05)$ and during the night $(r=0.45$, $\mathrm{p}<0.05)$. During cimetidine therapy there was no such correlation $(r=0.16$ for day, $r=0.11$ for night).

Further analysis also revealed that there was no change in the use of inhaled bronchodilator therapy between those patients whose peak flows were worse or unchanged. This suggests that alteration in bronchodilator therapy was not a significant factor with respect to improvement or deterioration of asthmatic symptoms during the trial period.

\section{Discussion}

It is well known that patients with established reflux may suffer from serious secondary pulmonary complications and that the dominant symptoms may be related to the respiratory rather than the gastrointestinal tract. ${ }^{12} 13$ Davies and Fiuzat ${ }^{14}$ demonstrated an improvement with respect to recurrent bronchopulmonary infections in infants and children after surgical repair at the gastro-oesophageal junction. More recently 
it has been reported that pulmonary fibrosis of obscure origin may be secondary to repeated small pulmonary aspirations associated with gastro-oesophageal incompetence. ${ }^{15}$ In addition gastropulmonary aspiration has been demonstrated by external gamma counting in patients with severe fibrotic lung disease associated with hiatus hernia or neurological disease. ${ }^{16}$ Undoubtedly, as stated by Kennedy, ${ }^{17}$ all patients with pulmonary infections or respiratory disease of obscure aetiology should be investigated for occult gastro-oesophageal reflux.

A possible relationship between bronchial asthma and reflux is less well defined. However, a high frequency of hiatus hernia with or without reflux in adults with bronchial asthma has been noted. ${ }^{418}$ The first point worthy of emphasis from our study is the ease with which 19 asthmatic patients with symptomatic reflux were found on routine questioning in a short period of time. On reviewing the histories, nine of these patients developed reflux symptoms before the onset of bronchial asthma. Ten patients were aware that an asthmatic episode was frequently preceded by severe reflux symptoms, eight patients noted no such relationship, and one thought that reflux symptoms developed as a result of the asthmatic attack.

The present study differs from previous reports in two important respects. Firstly, cimetidine has been used instead of antireflux surgery as a treatment because it is a potent inhibitor of gastric acid secretion reducing markedly both the volume and hydrogen ion concentration of gastric juice. ${ }^{1920}$ This study has shown that cimetidine was effective in relieving the symptoms of reflux in most of the patients. Furthermore, an improvement in asthmatic symptoms appears to have been associated with cimetidine therapy, particularly at night, a feature which might be expected if nocturnal reflux precipitates or aggravates respiratory symptoms. Three patients experienced such marked improvement in their respiratory symptoms while taking cimetidine that they have received a more prolonged course of this therapy with apparent benefit.

Secondly, an attempt has been made to demonstrate objective improvement with respect to respiratory function whereas previous work has only reported subjective benefit. Although quite comprehensive pulmonary function tests were performed, only the daily peak flow readings show a trend towards improvement. One of these reached statistical significance but it was disappointing that the magnitude of the improvement was so small. However, the subjective improvement experienced by most of the patients should not be ignored.

Gastro-oesophageal reflux as a trigger in bronchial asthma has been suggested in 25 out of 28 patients whose asthma was improved or completely relieved by surgical repair of hiatus hernia, although no objective evidence of the diagnosis of asthma or of subsequent improvement was given. ${ }^{2}$ Klotz and Moeller ${ }^{5}$ quoted five further patients whose asthma was alleviated by surgical or medical control of reflux. Mays ${ }^{18}$ in addition confirmed improvement in respiratory symptoms in patients with well-documented asthma by controlling reflux medically. It is interesting to speculate as to the possible mechanisms involved. If reflux can trigger bronchial asthma, is the mechanism simply one of intrapulmonary aspiration of refluxed gastric contents as suggested by $\mathrm{Babb}$ et al ${ }^{3}$ If so this is more likely to occur with the patient recumbent and therefore to give rise to nocturnal problems. Such a theory is attractive in that asthmatic patients with enhanced bronchomotor response to various irritant and pharmacological stimuli would be more likely to respond to even minute volumes of acid gastric contents within their lungs and subsequent stimulation of irritant receptors. ${ }^{21}$ However, evidence that microaspiration does take place in asthmatic patients is lacking, ${ }^{22}$ apart from one case of a child during a barium study. ${ }^{23}$ In our own experience two patients with severe asthma and reflux studied by the method of Reich et al, ${ }^{16}$ but with continuous external gamma counting throughout the night, failed to show any evidence of aspiration into the lungs despite frequent episodes of marked reflux.

A more attractive theory relating reflux and asthma has been put forward by Mansfield and Stein. ${ }^{24}$ Fifteen patients with established bronchial asthma and demonstrable reflux were studied before, during, and after infusion of $0.1 \mathrm{~N}$ hydrochloric acid into the oesophagus. There was undoubted subjective and objective evidence of bronchoconstriction associated with this acid infusion which improved after relief of symptoms with antacids. These authors postulate a vagal reflex, mediated by oesophageal receptors, which is responsible for the association between reflux and asthma.

It is unlikely that cimetidine has any direct effect upon bronchial smooth muscle by virtue of $\mathrm{H} 2$ receptor antagonism. Although it is thought that $\mathrm{H} 2$ receptors do exist in the human lung their role in the control of bronchoconstriction is far from clear. There is little doubt that histamine $\mathrm{H} 1$ receptors within the lung subserve broncho- 
constriction and the benefits of $\mathrm{Hl}$ antagonists have been well documented. ${ }^{25}{ }^{26}$ No study so far has shown any significant bronchodilator effect which could be attributed to cimetidine in either healthy or asthmatic subjects after histamine challenge. ${ }^{27} 28$ It is more likely, therefore, that any effects attributable to cimetidine in the present study are related to its action in reducing the volume and acidity of refluxed material into the body of the oesophagus. This would reduce the likelihood of associated bronchial asthma, whether the mechanism is one of pulmonary aspiration of oesophageal contents or a vagally mediated reflex.

Although asthma and reflux may be associated this does not imply that the reflux is necessarily the primary abnormality. Clemencon and Osterman $^{29}$ suggested that intrathoracic and intraabdominal pressure changes such as occur in acute asthma may induce reflux. Pellegrini et $a l^{30}$ have shown that an asthmatic attack or a bout of coughing may precede episodes of reflux. Thus a potential self-propagating situation can be envisaged where reflux, either by aspiration or a reflex mechanism, can aggravate asthma which itself can induce further reflux.

What, therefore, can we conclude about a relationship between reflux and asthma? There seems little doubt that controlling reflux may play a part in the management of asthma and that control of asthma may help reflux. We would suggest that at least in some patients nocturnal exacerbations of asthma could be related to acid entering the lower oesophagus. Certainly in patients in whom bronchial asthma is difficult to control, reflux should be considered and in a proportion of these patients medical or surgical correction of this reflux may have beneficial results with respect to their pulmonary problem.

We are grateful to North West Regional Health Authority for financial help and to Smith, Kline and French Ltd for supplies of the drugs. We would also like to acknowledge the help given to us by Dr D Rowley Jones, Jane Mills, and Dr David Daniels of Smith Kline and French Laboratories Ltd, and Dr Tito Testa, Dr Kingsley Brown, Dr Ray Bennet, Margaret Marples, Gillian Crook, Kim Lindley, Irene Lindsay and the staff of the Surgical Investigation Ward, Hope Hospital.

\section{References}

1 Belsey R. The pulmonary complications of oesophageal disease. Br J Dis Chest 1960; 54:
342-8.

2 Overholt RH, Ashraf MM. Esophageal reflux as trigger in asthma. NY State J Med 1966; 66: 3030-2.

3 Babb RR, Notarangelo J, Smith VM. Wheezinga clue to gastro-oesophageal reflux. Am J Gastroenterol 1970; 53:230-3.

4 Overholt RH, Vorhees RJ. Esophageal reflux as a trigger in asthma. Dis Chest 1966; 49:464-6.

5 Klotz SD, Moeller RK. Hiatal hernia and intractable bronchial asthma. Ann Allergy 1971; 29:325-8.

6 Goodall RJR, Temple JG. The effect of Nissen fundoplication on the lower oesophageal high pressure zone. Gut 1979; 20:A917.

7 Bernstein LM, Baker LA. A clinical test for oesophagitis. Gastroenterology 1958; 34:760-81.

8 DeMeester TR, Johnson LF. The evaluation of objective measurements of gastro-oesophageal reflux and their contribution to patient management. Surg Clin North Am 1976; 56:39-53.

9 Cotes JE. Lung function. Third edition. Oxford: Blackwell Press, 1975.

10 Koch GG. The use of non-parametric methods in the statistical analysis of the two-period change over design. Biometrics 1972; 28:577-84.

11 Hills M, Armitage P. The two-period cross-over clinical trial. Br J Clin Pharmacol 1979; 8:7-20.

12 Belcher JR. The pulmonary complications of dysphagia. Thorax 1949; 4:44-56.

13 Vivas JR, Palmer ED. Incidence of chronic pulmonary disease among patients with oesophageal disorders. Dis Chest 1957; 31:568-74.

14 Davis MV, Fiuzat J. Application of the Belsey hiatal hernia repair to infants and children with recurrent bronchitis, bronchiolitis and pneumonitis, due to regurgitation and aspiration. Ann Thorac Surg 1967; 3:99-110.

15 Mays EE, Dubois JJ, Hamilton GB. Pulmonary fibrosis associated with tracheo-bronchial aspiration. Chest 1976; 69:512-5.

16 Reich SB, Earley WC, Ravin TH, Goodman M, Spector S, Stein MR. Evaluation of gastropulmonary aspiration by a radio-active technique: concise communication. J Nucl Med 1977; 18: 1079-81.

17 Kennedy JH. "Silent" gastro-oesophageal reflux: an important but little known cause of pulmonary complications. Dis Chest 1962; 42:42-5.

18 Mays EE. Intrinsic asthma in adults. Association with gastro-oesophageal reflux. JAMA 1976; 236: 2626-8.

19 Henn RM, Isenberg JI, Maxwell V, Sturdevant RAL. Cimetidine inhibition of acid secretion in duodenal ulcer. $N$ Engl $J$ Med 1975; 293:371-5.

20 Pounder RE, Williams JG, Russell RCG, MiltonThompson GJ, Misiewicz JJ. Inhibition of foodstimulating gastric acid secretion by cimetidine. Gut 1976; 17:161-8.

21 Non-allergic provocation of asthma. Lancet 1975; 2:691-2.

22 Ghaed N, Stein MR. Assessment of a technique 
for scintigraphic monitoring of pulmonary aspiration of gastric contents in asthmatics with gastro-oesophageal reflux. Ann Allergy 1979; 42: 306-8.

23 Friedland GW, Yamate $M$, Marinkovich VA. Hiatal hernia and chronic unremitting asthma. Pediatr Radiol 1973; 1:156-60.

24 Mansfield LE, Stein MR. Gastro-oesophageal reflux and asthma: a possible reflex mechanism. Ann Allergy 1978; 41:224-6.

25 Nogrady SG, Bevan C. Inhaled antihistaminesbronchodilation and effects of histamine and metacholine-induced bronchoconstriction. Thorax 1978; 33:700-4.

26 Nogrady SG, Hartley JPR, Handslip PDJ, Hurst NP. Bronchodilation after inhalation of the antihistamine clemastine. Thorax 1978; 33:479-82.
27 Maconochie JG, Woodings EP, Richards DA. Effects of H1- and H2-receptor blocking agents on histamine-induced bronchoconstriction in nonasthmatic subjects. Br J Clin Pharmacol 1979; 7:231-6.

28 Eiser NM, MacRae KD, Guz A. Bronchial histamine receptors in normal, atopic and asthmatic subjects. Thorax 1979; 34:703.

29 Clemencon GH, Osterman PO. Hiatal hernia in bronchial asthma-the importance of concomitant pulmonary emphysema. Gastroenterologia 1961; 95:110-20.

30 Pellegrini CA, DeMeester TR, Johnson IF, Skinner DB. Gastro-oestophageal reflux and pulmonary aspiration: incidence, functional abnormality and results of surgical therapy. Surgery 1979; 86:110-8. 